Studi Francesi

STUDI

Rivista quadrimestrale fondata da Franco Simone

179 (LX | II) | 2016

Varia

\title{
Ronjaunee Chatterjee, Baudelaire and Feminine Singularity
}

Maria Emanuela Raffi

\section{CpenEdition}

Journals

Edizione digitale

URL: http://journals.openedition.org/studifrancesi/4438

DOI: 10.4000/studifrancesi.4438

ISSN: 2421-5856

Editore

Rosenberg \& Sellier

\section{Edizione cartacea}

Data di pubblicazione: 1 settembre 2016

Paginazione: 356

ISSN: 0039-2944

Notizia bibliografica digitale

Maria Emanuela Raffi, « Ronjaunee Chatterjee, Baudelaire and Feminine Singularity », Studi Francesi

[Online], 179 (LX | II) | 2016, online dal 01 septembre 2016, consultato il 18 septembre 2020. URL

http://journals.openedition.org/studifrancesi/4438 ; DOI : https://doi.org/10.4000/studifrancesi.4438

Questo documento è stato generato automaticamente il 18 settembre 2020.

\section{c)}

Studi Francesi è distribuita con Licenza Creative Commons Attribuzione - Non commerciale - Non opere derivate 4.0 Internazionale. 


\title{
Ronjaunee Chatterjee, Baudelaire and Feminine Singularity
}

\author{
Maria Emanuela Raffi
}

\section{NOTIZIA}

RONJAUNEE CHATTERJEE, Baudelaire and Feminine Singularity, in «French Studies» 70, 1, 2016, pp. 17-32.

1 Partendo dalle affermazioni diffuse fra i critici baudelairiani sulla misoginia o per lo meno sull'ambivalenza nei confronti del femminile da parte dell'autore delle Fleurs du mal, Ronjaunee Chatterjee sostiene l'inseparabilità della questione dalla visione complessiva di Baudelaire nella Parigi di Haussmann, che non stravolge solo le strade e la città, ma anche il modo di concepire le relazioni umane e la propria stessa identità personale. Secondo l'A., la figura femminile si colloca nell'opera di Baudelaire all'incrocio di due importanti fenomeni: «firstly, the development of capital, and secondly, the political grounding of the liberal subject». Collocata alla convergenza dell'unico e del molteplice, la «feminine singularity», come la definisce l'A., è percepibile in figure come la protagonista di À une passante, o ancora in Les Sept Vieillards, Les Petites Vieilles e Le Cygne. L'unicità, in tutte queste poesie, si oppone apertamente alla molteplicità e a una sorta di possibile infinito, ma la rappresentazione maschile e femminile di tale infinito appare radicalmente differente: $\mathrm{i}$ «Vieillards» sono terrificanti e tutti uguali, portatori di un'immagine paterna minacciosa e ripetitiva, mentre le «Petites vieilles» sono viste nella loro singolarità, sia pure attraverso un comune destino: «I would venture to say it is the art of modern women in the sense that it recognizes itself in a proliferation of fugitive feminine figures without a common model, without reference to la femme en général». 